\title{
Role of Burkholderia pseudomallei- Specific IgG2 in Adults with Acute Melioidosis, Thailand
}

\author{
Panjaporn Chaichana, Kemajittra Jenjaroen, Suchintana Chumseng, \\ Manutsanun Sumonwiriya, Patpong Rongkard, Barbara Kronsteiner, Prapit Teparrukkul, \\ Direk Limmathurotsakul, Nicholas P.J. Day, Narisara Chantratita, Susanna J Dunachie
}

Melioidosis is a life-threatening infectious disease caused by the gram-negative bacillus Burkholderia pseudomallei. An effective vaccine is needed, but data on protective immune responses in human melioidosis are lacking. We used ELISA and an antibody-dependent cellular phagocytosis assay to identify the major features of protective antibodies in patients with acute melioidosis in Thailand. We found that high levels of $B$. pseudomallei-specific IgG2 are associated with protection against death in a multivariable logistic regression analysis adjusting for age, diabetes, renal disease, and neutrophil count. Serum from melioidosis survivors enhanced bacteria uptake into human monocytes expressing FcyRIla-H/R131, an intermediate-affinity lgG2-receptor, compared with serum from nonsurvivors. We did not find this enhancement when using monocytes carrying the low IgG2-affinity Fc $\gamma$ Rlla-R131 allele. The findings indicate the importance of IgG2 in protection against death in human melioidosis, a crucial finding for antibody-based therapeutics and vaccine development.

$\mathrm{M}$ elioidosis is a major cause of fatal communityacquired septicemia in highly endemic areas, including northeast Thailand and north Australia $(1,2)$. Melioidosis is now known to be endemic in $\geq 45$ countries across tropical regions (3). A formal modeling framework predicted the global burden to be 165,000 human melioidosis cases per year, with a case-fatality rate of $54 \%$. The causative agent of melioidosis, the highly pathogenic gram-negative bacillus

Author affiliations: Mahidol-Oxford Tropical Medicine Research Unit, Bangkok, Thailand (P. Chaichana, K. Jenjaroen,

S. Chumseng, M. Sumonwiriya, P. Rongkard, D. Limmathurotsakul, N.P.J. Day, N. Chantratita, S.J. Dunachie); University of Oxford,

Oxford, England (P. Rongkard, B. Kronsteiner, D. Limmathurotsakul,

N.P.J. Day, S. Dunachie); Sunpasithiprasong Hospital, Ubon

Ratchathani, Thailand (P. Teparrukkul)

DOI: https://doi.org/10.3201/eid2702.200213
Burkholderia pseudomallei, is classified as a Tier 1 Select Agent by the US Centers for Disease Control and Prevention (https://www.cdc.gov/selectagent/index. $\mathrm{html})$. B. pseudomallei intrinsically is resistant to firstline commonly available antimicrobial drugs, making a prophylactic vaccine the most desirable approach for disease control.

Growing evidence supports the effects of cellular adaptive immunity in human defense against B. pseudomallei infection (4-6), but additional evidence also points to the role of protective antibodies against fatal melioidosis. For instance, animal studies have demonstrated that passive transfer of antibodies specific to the bacterial lipopolysaccharide (LPS) or capsular polysaccharide (CPS) can protect mice (7-9) or a diabetic rat model (10) from intranasal or intraperitoneal challenge of B. pseudomallei at lethal doses. Intraperitoneal or subcutaneous immunization of mice with B. pseudomallei LPS, CPS (11), or CPS covalently linked to recombinant CRM197 diphtheria toxin mutant (CPS-CRM197) plus hemolysin coregulated protein 1 (Hcp1) (12) provided an optimal protective antibody response. In addition, results from studies of human melioidosis patients demonstrated that elevated levels of anti-oligo polysaccharide (OPS) II (13) and anti-LPSII IgG (14) were correlated with survival. Previous studies demonstrated that IgG1 and IgG2 are the predominant antibodies in response to the culture filtrate antigen $(15,16)$. A recent study in a population from the same region showed differences in IgG subclass effects in response to 2 key antigens in $B$. pseudomallei, Hcp1 and OPS (17), and IgG3 responses to Hcp1 correlated with melioidosis survival. However, little data on the mechanistic effects of IgG subclasses in human melioidosis are available.

Clarifying the mechanistic role of immunoglobulin-mediated protection against melioidosis would 
provide crucial information for developing an effective vaccine and therapeutic monoclonal antibodies. We report on the role of $B$. pseudomallei-specific IgG2 subclass and its high binding activating Fc gamma receptor $(\mathrm{Fc \gamma})$ IIa polymorphism $\mathrm{H} 131$ in protection against death in human melioidosis during the acute phase.

\section{Materials and Methods}

\section{Ethics Statement}

The study was approved by the ethics committees of the Faculty of Tropical Medicine, Mahidol University (submission no. TMEC 12-014) and Sunpasithiprasong Hospital, Ubon Ratchathani (reference no. 018/2555), and by the Oxford Tropical Research Ethics Committee (reference no. 64-11). We conducted the study according to the principles of the Declaration of Helsinki 2008 (https://www.wma.net) and the International Conference on Harmonization Good Clinical Practice guidelines (https://ichgcp. net). We received written informed consent from all patients enrolled in the study.

\section{Serum Sample Collection}

We enrolled 200 adult inpatients with acute melioidosis $\geq 18$ years of age at Sunpasithiprasong Hospital at a median of 5 days (range 2-13 days; interquartile range [IQR] 3-6 days) after admission, as described previously $(4,18)$. We recruited healthy controls among donors at the hospital's blood donation clinic. We defined melioidosis as isolation of B. pseudomallei from any clinical sample submitted to the laboratory, including blood, sputum, pus, urine, throat or endotracheal swabs, or bronchoalveolar lavage. Among 200 enrolled patients, 6 patients were lost to followup, with survival status unknown, so they were excluded from the analysis. Of 194 patients included, 61 had insufficient stored serum specimens for IgG subclass assays; hence, we analyzed serum samples from 139 subjects.

\section{Antigen Preparation}

We prepared whole-cell antigen from wild type strain B. pseudomallei K96243, an isolate from a patient in northeast Thailand, which was modified from a previous study $(19,20)$. In brief, we grew the bacteria in rice medium at $37^{\circ} \mathrm{C}$ for 14 days, then heat-inactivated the bacteria at $121^{\circ} \mathrm{C}$ for $30 \mathrm{~min}$. We centrifuged the wholecell heat-inactivated (HIA) B. pseudomallei at 2,000 $\times g$ for $1 \mathrm{~h}$, then used the supernatant as an antigen. We aliquoted and kept the supernatant at $-20^{\circ} \mathrm{C}$ until used. We quantitated the protein concentration of the antigens in the supernatant by using the Pierce BCA Protein Assay Kit (Thermo Fisher Scientific, https:/ / www.thermofisher.com) according to the manufacturer's protocol.

\section{ELISA}

We used ELISA to measure serum levels of IgM and IgG specific to B. pseudomallei. We added whole cells of HIA B. pseudomallei to wells of Nunc MaxiSorp flat bottom 96-Well immunoplates (Thermo Fisher Scientific) at a concentration of $200 \mathrm{ng} /$ well and incubated the plates overnight at $4^{\circ} \mathrm{C}$. Between each step, we washed the ELISA plate 3 times with $300 \mu \mathrm{L}$ of washing buffer consisting of $0.05 \%$ Tween-20 in phosphate buffered saline (PBS; Sigma-Aldrich, https://www. sigmaaldrich.com). After blocking with 5\% skimmed milk in PBS for $2 \mathrm{~h}$ at $37^{\circ} \mathrm{C}$, we diluted the serum 1:100 and added it to the plate in duplicate, then incubated for $1 \mathrm{~h}$. We diluted the horseradish peroxidase (HRP) enzyme-conjugated antihuman IgM or IgG (SigmaAldrich) 1:2,000 and then added it to the ELISA plate before incubating for $1 \mathrm{~h}$. We developed the ELISA by using 3,3',5,5'-tetramethylbenzidine (TMB; Thermo Fisher Scientific) substrate and determined the absorbance value (optical density $=450 \mathrm{~nm}$ ) by using a Multiskan GO microplate spectrometer (Thermo Fisher Scientific).

For IgG subclasses, we blocked the overnight precoated ELISA plate with $1 \%$ bovine serum albumin (BSA) in PBS for $2 \mathrm{~h}$. We then diluted the serum 1:100 for detecting IgG1, IgG3, and IgG4 or 1:2,000 for detecting IgG2, and then added the serum to the ELISA plate. After 1-h incubation, we diluted the biotin-conjugated antihuman IgG1, IgG2, IgG3, or IgG4 1:1,000 and added them to the plate before incubating for $1 \mathrm{~h}$. Then we added streptavidin-HRP (Mabtech, https:/ / www.mabtech.com) to the plate and incubated for 1 $h$ and developed by using TMB as we described in the previous paragraph.

\section{Genomic Methods}

We extracted genomic DNA from blood samples by using the QIAamp DNA Blood Midi kit (QIAGEN, https://www.qiagen.com) according to the manufacturer's instructions, then stored at $-20^{\circ} \mathrm{C}$. We genotyped the FCGR2A c.535A>G (rs1801274) single nucleotide variant (SNV) by using the TaqMan SNP genotyping assay (Applied Biosystems, https://www.thermofisher.com) on a CFX96 Touch Real-Time PCR Detection System (Bio-Rad, http:// www.bio-rad.com). The SNV context sequence was AATGGAAAATCCCAGAAATTCTCCC $($ A/G) TTTGGATCCCACCTTCTCCATCCCA. 


\section{Antibody-Dependent Cellular Phagocytosis}

We labeled the bacteria by incubating with fluorescein isothiocyanate (FITC) for $30 \mathrm{~min}$ in the dark at room temperature, then washed the bacteria with PBS and immediately used the bacteria in the assay. We incubated FITC-labeled B. pseudomallei with HIA serum samples (10\% vol/vol) or Roswell Park Memorial Institute (RPMI) 1640 medium (Sigma-Aldrich) as a control at $37^{\circ} \mathrm{C}$ for $1 \mathrm{~h}$. We then added opsonized FITC-labeled B. pseudomallei to human monocyte cell lines, THP-1 (FcyRIIa-R-H131 genotype) or U937 (FcyRIIa-R131 genotype), at a multiplicity of infection (MOI) of 5 CFUs/ cell. After incubation at $37^{\circ} \mathrm{C}$ for $30 \mathrm{~min}$, we immediately transferred cells to ice to stop phagocytosis. We washed the cells twice with cold PBS. We then added cold trypan blue (Sigma-Aldrich) to the cells and incubated for $10 \mathrm{~min}$ on ice to quench the FITC signal of bound B. pseudomallei on cell surface. Next, we washed the cells twice with cold PBS and incubated with BD Cytofix Fixation Buffer (Becton Dickinson, https:/ / www. bd.com) cold fixative buffer at $4^{\circ} \mathrm{C}$ for $15 \mathrm{~min}$. We then washed the cells twice with cold MACSQuant Running Buffer (Miltenyi Biotec, https://www.miltenyibiotec. com), and analyzed the cells by using the MACSQuant Analyzer 10 (Miltenyi Biotec). We expressed results as fold-change in enhancement of phagocytosis calculated by dividing the percentage of infected cells in the presence of serum by those in the absence of serum samples in the RPMI-1640 control.

\section{Statistics}

We reported nonnormally distributed continuous data as median and IQR. We analyzed the statistical significance of differences by using Mann-Whitney U-test for 2 groups and the Kruskal-Wallis 1-way ANOVA to test the mean difference among 3 groups in GraphPad Prism Version 6 (GraphPad Software Inc., https:/ / www.graphpad.com). We calculated the percentage of coefficient of variation (CV) in ELISA by dividing SD of measurement by mean of measurement multiplied by 100 . The cutoff was $10 \%$ intraassay CV and $15 \%$ for inter-assay CV. We performed univariable and multivariable logistic regression adjusting for age, diabetes, pre-existing renal disease, and neutrophil counts by using Stata version 14.0 for Windows (StataCorp LLC, https:/ / www.stata.com).

\section{Results}

\section{Elevated IgG2 Levels in Patients Who Survived Melioidosis}

The characteristics of patients with acute melioidosis enrolled in the study were previously described $(4,18)$.
Among 194 patients in the cohort, median age was 56 years (range 19-89 years; IQR 46-63 years); 129 (66.5\%) were men and $65(33.5 \%)$ were women. Underlying conditions among patients included diabetes (57.7\%), renal disease $(17.5 \%)$, and heart disease $(11.8 \%)$ (Table 1). Forty-nine (25\%) persons died within 28 days despite receiving appropriate antimicrobial drug treatment.

Serum levels of IgM specific to whole-cell HIA $B$. pseudomallei were not statistically significantly different between survivors (median 0.28, IQR 0.13-1.00) and nonsurvivors (median 0.31, IQR 0.08-0.52; $\mathrm{p}=$ 0.18) (Figure 1, panel A). Similarly, anti-HIA B. pseudomallei IgG levels were not different between survivors (median 2.32, IQR 1.10-2.94) and nonsurvivors (median 2.12, IQR 1.42-2.50; $\mathrm{p}=0.29$ ) (Figure 1, panel B). As expected, HIA B. pseudomallei-specific IgM and IgG levels in patients with melioidosis, including those who died and survived, were much higher than those in healthy controls (Figure 1, panels A, B).

We then measured anti-HIA B. pseudomallei IgG subclasses in serum samples from melioidosis patients to determine whether IgG subclasses are associated with survival. We found statistically significantly higher IgG2 levels (median 1.30, IQR 0.45-2.04) against whole-cell heat-killed B. pseudomallei in serum from survivors than in serum from nonsurvivors (median 0.59, IQR 0.26-1.51; $\mathrm{p}=0.047$ ) (Figure 1, panel D). Levels of IgG1, IgG3, and IgG4 subclasses were comparable between groups (Figure 1, panels C, E, F).

\section{IgG2 Level Associated with Protection against Death}

In a univariable model, we found that increasing IgG2 levels in serum samples was statistically significantly associated with survival (odds ratio [OR] 0.63, 95\% CI $0.43-0.92)$. In previous studies of the same cohort, we found that age, pre-existing renal disease, and neutrophil count were associated with a 28-day mortality rate of $26 \%(4,18)$. We next tested the association of the IgG2 levels with death by using a multivariable

\begin{tabular}{lc}
\hline \multicolumn{2}{l}{ Table 1. Baseline demographic characteristics of patients with } \\
acute melioidosis, Thailand \\
\hline Characteristic & No. patients (\%), $\mathrm{n}=194$ \\
\hline Deaths & $49(25.3)$ \\
Median age, y (IQR) & $56(46-63)$ \\
\hline Sex & $129(66.5)$ \\
M & $65(33.5)$ \\
F & \\
\hline Underlying conditions & $112(57.7)$ \\
Diabetes & $34(17.5)$ \\
Renal disease & $23(11.8)$ \\
Heart disease & $7(3.6)$ \\
Chronic liver disease & $5(2.6)$ \\
\hline Previous melioidosis & \\
\hline Clinical manifestation & $99(51.0)$ \\
Bacteremia & $48(24.7)$ \\
Pneumonia &
\end{tabular}



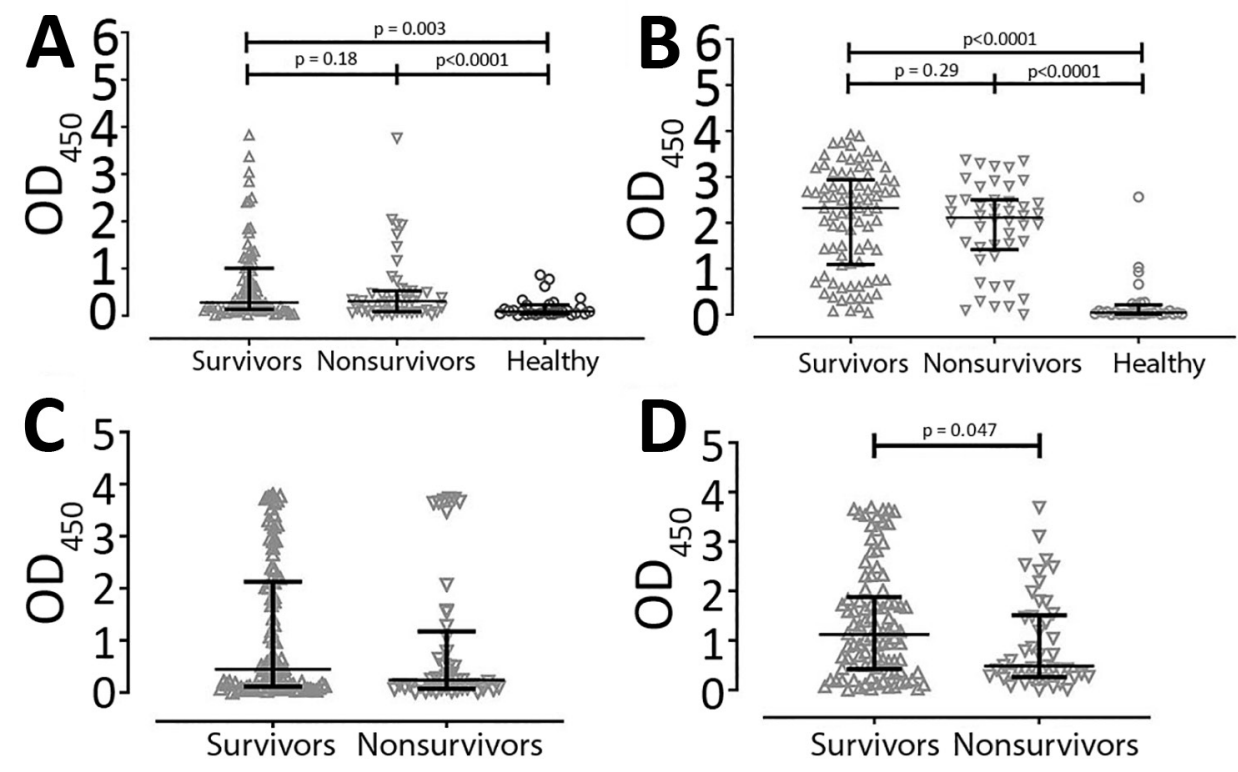

Figure 1. Comparison of serum levels of Burkholderia pseudomallei-specific antibody subclasses between 94 survivors and 45 nonsurvivors of acute melioidosis, Thailand. A) IgM; B) total IgG; C) IgG1; D) IgG2; E) IgG3; and F) IgG4. Serum levels were tested by using indirect ELISA on heat-killed whole cell B. pseudomallei. We used Kruskal-Wallis 1-way ANOVA to compare $>2$ groups and MannWhitney $U$ to compare 2 groups. Antibody levels in healthy endemic controls $(n=30)$ are shown for comparison for total $\operatorname{lgM}$ and $\lg \mathrm{G}$ only. $\mathrm{OD}_{450}$, optical density at $450 \mathrm{~nm}$.
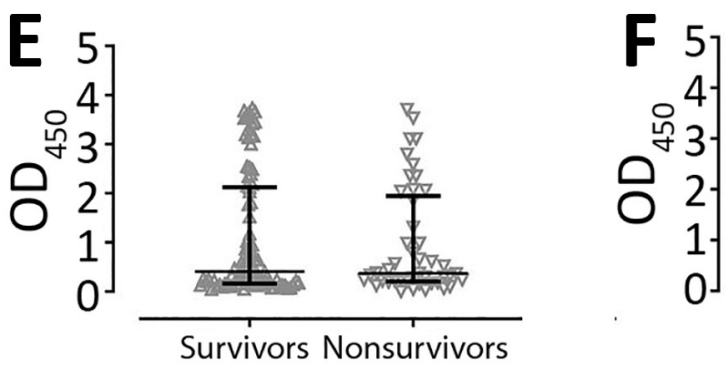

Survivors Nonsurvivors

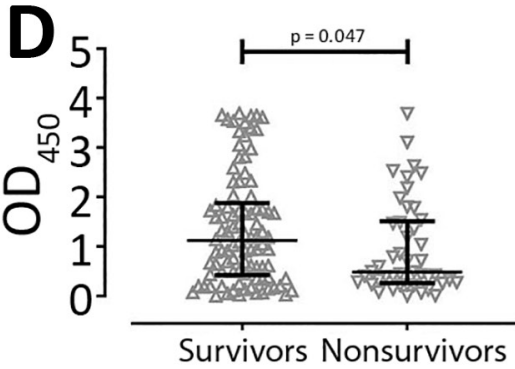

model adjusting for age, diabetes, pre-existing renal disease, and neutrophil count (Table 2). Our results demonstrate that elevated IgG2 levels correlate with survival (OR 0.50, 95\% CI 0.30-0.83).

\section{Serum from Survivors Enhanced Phagocytosis in THP-1 Human Monocytic Cells}

IgG2 has the least functional potency of the subclasses due to low affinity binding between its Fc region and activating $F_{c} \gamma$ Rs expressed on effector innate immune cells $(21,22)$. A single-nucleotide polymorphism (SNP) resulting in a histidine $(\mathrm{H})$ residue instead of

\begin{tabular}{lcc}
\hline \multirow{2}{*}{$\begin{array}{l}\text { Table 2. Multivariable-adjusted logistic regression for melioidosis } \\
\text { mortality rates, Thailand* }\end{array}$} \\
\hline \multirow{2}{*}{ Variable } & Mortality rate \\
\cline { 2 - 3 } Serum IgG2 level & Adjusted OR $(95 \% \mathrm{Cl})$ & $\mathrm{p}$ value \\
Age $\geq 45 \mathrm{y}$ & $0.50(0.30-0.83)$ & 0.007 \\
Diabetes & $0.36(0.10-1.30)$ & 0.120 \\
Preexisting renal disease & $0.92(0.34-2.53)$ & 0.876 \\
\hline Neutrophil count/ $/ \mathrm{L}$ & $9.41(2.48-35.80)$ & 0.001 \\
$\quad>4,000-8,000$ & Referent & $<0.001$ \\
$\leq 4,000$ & $4.66(0.52-41.50)$ & \\
$>8,000-12,000$ & $19.00(3.40-106.33)$ \\
$\geq 12,000$ & $14.78(2.78-78.73)$ \\
\hline${ }^{*} \mathrm{OR}$, odds ratio. &
\end{tabular}

an arginine $(\mathrm{R})$ at position 131 improves affinity for human IgG2 and affects effector function (23). We performed antibody-dependent cellular phagocytosis (ADCP) assays by using 2 monocyte cell lines: U937 cells, containing a homozygous low-affinity R131 allele, and THP-1 cells, containing heterozygous intermediate-affinity H/R131 alleles of FcyRIIa.

The ADCP activities of antibodies were not statistically significantly different between serum from survivors (median 37.63, IQR 19.88-82.62) and nonsurvivors (median 45.34, IQR 21.51-93.67) in U937 containing the low-affinity FcyRIIa-R131 phenotype ( $p$ $=0.68$ ) (Figure 2, panel A). In contrast, we did find a statistically significant difference in phagocytic activity between survivors (median 89.66, IQR 69.03-120.30) and nonsurvivors (median 52.43, IQR 37.14-105.10) when we used THP-1 expressing intermediate affinity FcyRIIA-H/R131 (p<0.001) (Figure 2, panel B).

\section{Association between Enhanced \\ Phagocytosis in THP-1 and Bacteremia}

When we used U937 cells, we did not see a statistically significant difference in ADCP activity between patients without bacteremia (median 60.95, 
Figure 2. Comparison of antibody-dependent cellular phagocytosis (ADCP) activity between 82 survivors and 38 nonsurvivors of acute melioidosis, Thailand. ADCP activity was tested by using U937 (A) and THP-1 (B) human monocytic cell lines. Heatinactivated serum samples were incubated with live fluorescein isothiocyanatelabeling Burkholderia pseudomallei before transfer to the cells, and the percentage of B. pseudomallei uptake by cells was analyzed by flow cytometer. We used the Mann-Whitney $U$ test for statistical comparison.
IQR 18.18-93.38) and those with bacteremia (median 30.68, IQR 20.22-76.03; $p=0.12$ ) (Figure 3, panel A). Furthermore, the ADCP activity in THP-1 of serum from patients without bacteremia (median 90.18, IQR 61.62-135.5) was higher than in those with bacteremia (median 75.38, IQR 41.39-106.80), but this difference did not reach statistical significance $(p=0.07)$ (Figure 3, panel B).

\section{FcyRlla Genotype Distribution among Cohort Patients} The genotype distribution was 63.4\% FcyRIIaH131/H131, 29.3\% FcyRIIa-H131/R131, and 7.3\% FcyRIIa-R131/R131 and exhibited a 9:4:1 ratio in our melioidosis cohort. The frequency of the Fc $\gamma$ RIIa-H131 allele overall in our cohort was 78\%. However, we did not find a substantial association between this FcyRIIa polymorphism and death, bacteremia, diabetes status, or preexisting renal disease in our cohort (data not shown).

\section{Discussion}

Our major finding in this study is the elevated level of serum IgG2 against whole-cell HIA B. pseudomallei lysate in melioidosis patients who survived the disease compared with fatal cases. We confirmed the association between elevated IgG2 level and survival in a multivariable logistic regression analysis adjusting for age, diabetes, preexisting renal disease, and neutrophil count. Some studies provide evidence for a role of IgG2 in protection against various microorganismal infections, including Plasmodium falciparum malaria (24), and encapsulated bacteria, including Streptococcus pneumoniae $(25,26)$, Haemophilus influenza $(26,27)$, and Neisseria meningitidis (28). The IgG2 in those studies mainly recognized CPS epitopes that are highly repeated T-independent antigens. Previous work did not show a correlation between IgG2 responses to Hcp1 or OPS and survival (14), so the IgG2 responses to whole-cell B. pseudomallei in our study are likely to be against other antigens yet to be tested. Ongoing work also will address whether protective IgG2 also bind to carbohydrate epitopes on the outside surface of Burkholderia spp.

A large body of literature supports IgG2 having no or lower relative binding affinity for activating $F_{c} \gamma R s$ when compared with other IgG subclasses $(21,29)$. Nevertheless, IgG2 has been shown to possess opsonophagocytosis capacity in some studies $(27,28,30)$. These conflicting results might be explained by the presence of a guanine to adenine SNP resulting in replacement
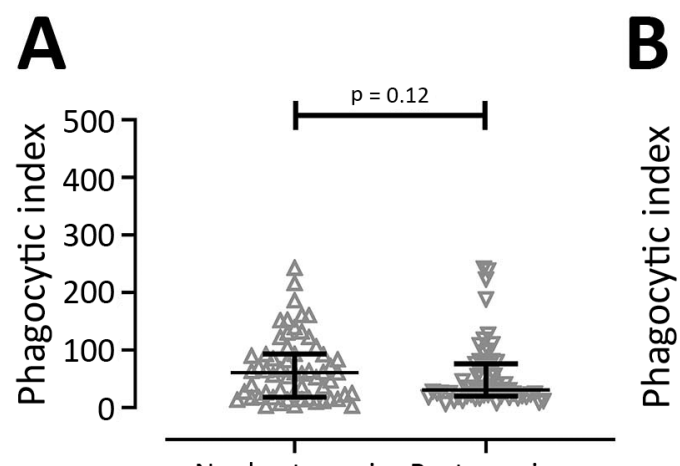

Nonbacteremia Bacteremia
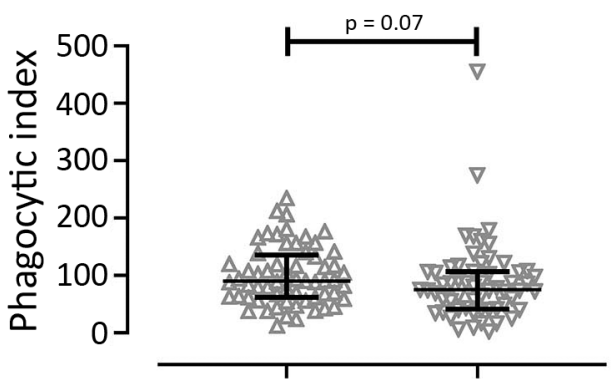

Nonbacteremia Bacteremia
Figure 3. Comparison of antibody-dependent cellular phagocytosis (ADCP) activity between 61 patients without bacteremia and 59 patients with bacteremia among patients with acute melioidosis, Thailand. ADCP activity was tested by using U937 (A) and THP-1 (B) human monocytic cell lines. We used the Mann-Whitney U test for statistical comparison. 
of arginine (R) with histidine $(\mathrm{H})$ at residue 131 of FcyRIIa. The product of FcyRIIa-H131, which has been reported in $67 \%$ of persons with Chinese ethnicity (31), $45 \%$ of White populations, and $41 \%$ of Black populations (32), were found to bind IgG2-immune complex more efficiently than those of R131 $(33,34)$, hence enhancing phagocytosis. Therefore, the considerable association between elevated IgG2 and protection against death in this cohort could be partly due to an increase of IgG2-mediated phagocytosis of the bacteria to effector innate immune cells via FcyRIIA, which $78 \%$ of our cohort possessed.

We used 2 types of human monocytic cells expressing different FcyRIIa phenotypes to compare ADCP activity between patients who survived the disease and those who did not. U937 cells are homozygous for low-affinity FcyRIIa-H/R131 phenotype, whereas THP-1 cells are heterozygous for intermediate-affinity $\mathrm{Fc}_{\mathrm{C}} \mathrm{RIIa}-\mathrm{H} / \mathrm{R} 131$ phenotype. We demonstrated that serum from survivors with much higher levels of IgG2 subclass could enhance B. pseudomallei uptake into THP-1 cells compared with those from nonsurvivors. Conversely, we did not find a difference in ADCP activity in U937 cells between survivors and nonsurvivors. When using U937 cells, comparable phagocytic activities of serum samples between survivors and nonsurvivors might be due to the comparable levels of IgG1or IgG3 that can effectively interact with FcyRIIa-R131. The phagocytic activities of IgG1 and IgG3 imply that higher IgG2 levels can enhance ADCP activity in effector innate immune cells carrying the FcyRIIa-H131 allele and that this ADCP activity was associated with protection against death in acute melioidosis patients.

Elevated ADCP activity of serum samples from patients without bacteremia almost reached statistical significance $(p=0.07)$ compared with those from patients with bacteremia when we used THP-1 cells but not when we used U937 cells. The ADCP activity results imply that the immune complex in circulating blood can be removed more effectively in persons with the Fcy RIIa-H131 phenotype.

One limitation of this study is that we used different cell types, which might have different genetic and phenotypic backgrounds resulting in different outcomes of ADCP activity in serum from survivors and nonsurvivors. This finding should be confirmed in U937 cells transfected with the FcyRIIa-H131 receptor. In addition, IgG2 serum samples from patients also contain the other 3 IgG subclasses, IgG1, IgG3, and IgG4, and IgM and IgA that might influence outcomes. In addition, the antibody-dependent phagocytosis activity of serum in this study was tested solely in human monocytic cells, U937 and THP-1, whereas FcyRIIa also is constitutively expressed on the surface of other effective immune cells including dendritic cells, neutrophils, and B cells.

We did not find a statistically significant association between FcyRIIa-H131 phenotype and ADCP activity in either THP-1 or U937 cells when adjusting for death, diabetes status, and pre-existing renal disease. This result might be due to a low number of patients with the FcyRIIa-R131 phenotype (7.3\%) in our cohort; therefore, we did not have the statistical power to detect a difference in outcome.

In conclusion, the data in this study emphasize the role of IgG subclasses in clinical outcomes of infectious diseases. The relationship between elevated IgG2 levels and protection against death in melioidosis is comparable with those in other encapsulated bacterial infections. The relationship between elevated IgG2 levels and protection against death in melioidosis constitutes critical information for selecting the appropriate antibody subclasses for therapeutic antibody and vaccine development, in particular for patients with the FcyRIIa-H131 phenotype.

\section{Acknowledgments}

We are grateful for the help and support from all participants and staff at Sunpasitthiprasong Hospital and the Mahidol-Oxford Tropical Medicine Research Unit (MORU), which receives core support from the Wellcome Trust.

P.C. received financial support from the Global Challenges Research Fund Networks in Vaccines Research and Development VALIDATE Network, which was cofunded by the Medical Research Council and Biotechnology and Biological Sciences Research Council, a funding award from the United Kingdom that is part of the European \& Developing Countries Clinical Trials Programme 2 and supported by the European Union. S.J.D. received financial support from Wellcome Trust Intermediate Clinical Fellowship award (no. WT100174/Z/12/Z).

\section{About the Author}

Dr. Chaichana is a postdoctoral fellow at Mahidol-Oxford Tropical Medicine Research Unit, Mahidol University, Bangkok, Thailand. Her research interests focus on the humoral immune response and antibody-based therapeutics to tropical bacterial diseases.

\section{References}

1. Currie BJ, Fisher DA, Howard DM, Burrow JN, Lo D, SelvaNayagam S, et al. Endemic melioidosis in tropical northern Australia: a 10-year prospective study and review of the 
literature. Clin Infect Dis. 2000;31:981-6. https://doi.org/ 10.1086/318116

2. Chaowagul W, White NJ, Dance DA, Wattanagoon $Y$, Naigowit P, Davis TM, et al. Melioidosis: a major cause of community-acquired septicemia in northeastern Thailand. J Infect Dis. 1989;159:890-9. https:/ / doi.org/10.1093/ infdis/159.5.890

3. Limmathurotsakul D, Golding N, Dance DAB, Messina JP, Pigott DM, Moyes CL, et al. Predicted global distribution of Burkholderia pseudomallei and burden of melioidosis. Nat Microbiol. 2016;1:15008. PubMed https://doi.org/10.1038/ nmicrobiol.2015.8

4. Jenjaroen $K$, Chumseng S, Sumonwiriya M, Ariyaprasert P, Chantratita N, Sunyakumthorn P, et al. T-cell responses are associated with survival in acute melioidosis patients. PLoS Negl Trop Dis. 2015;9:e0004152. https:/ / doi.org/10.1371/ journal.pntd.0004152

5. Nithichanon A, Rinchai D, Buddhisa S, Saenmuang P, Kewcharoenwong C, Kessler B, et al. Immune control of Burkholderia pseudomallei-common, high-frequency T-cell responses to a broad repertoire of immunoprevalent epitopes. Front Immunol. 2018;9:484. https:/ / doi.org/ 10.3389/fimmu.2018.00484

6. Tippayawat P, Pinsiri M, Rinchai D, Riyapa D, Romphruk A, Gan YH, et al. Burkholderia pseudomallei proteins presented by monocyte-derived dendritic cells stimulate human memory T cells in vitro. Infect Immun. 2011;79:305-13. https://doi.org/10.1128/IAI.00803-10

7. Jones SM, Ellis JF, Russell P, Griffin KF, Oyston PCF. Passive protection against Burkholderia pseudomallei infection in mice by monoclonal antibodies against capsular polysaccharide, lipopolysaccharide or proteins. J Med Microbiol. 2002;51:1055-62. https:/ / doi.org/10.1099/ 0022-1317-51-12-1055

8. Bottex C, Gauthier YP, Hagen RM, Finke EJ, Splettstösser WD, Thibault FM, et al. Attempted passive prophylaxis with a monoclonal anti-Burkholderia pseudomallei exopolysaccharide antibody in a murine model of melioidosis. Immunopharmacol Immunotoxicol. 2005;27:56583. https:// doi.org/10.1080/08923970500493995

9. AuCoin DP, Reed DE, Marlenee NL, Bowen RA, Thorkildson P, Judy BM, et al. Polysaccharide specific monoclonal antibodies provide passive protection against intranasal challenge with Burkholderia pseudomallei. PLoS One. 2012;7:e35386. https:// doi.org/10.1371/journal.pone .0035386

10. Bryan LE, Wong S, Woods DE, Dance DA, Chaowagul W. Passive protection of diabetic rats with antisera specific for the polysaccharide portion of the lipopolysaccharide isolated from Pseudomonas pseudomallei. Can J Infect Dis. 1994;5:170-8. https:/ / doi.org/10.1155/1994/856850

11. Nelson M, Prior JL, Lever MS, Jones HE, Atkins TP, Titball RW. Evaluation of lipopolysaccharide and capsular polysaccharide as subunit vaccines against experimental melioidosis. J Med Microbiol. 2004;53:1177-82. https://doi.org/10.1099/jmm.0.45766-0

12. Burtnick MN, Shaffer TL, Ross BN, Muruato LA, Sbrana E, DeShazer D, et al. Development of subunit vaccines that provide high-level protection and sterilizing immunity against acute inhalational melioidosis. Infect Immun. 2017;86:e00724-17. https:// doi.org/10.1128/IAI.00724-17

13. Ho M, Schollaardt T, Smith MD, Perry MB, Brett PJ, Chaowagul W, et al. Specificity and functional activity of anti-Burkholderia pseudomallei polysaccharide antibodies. Infect Immun. 1997;65:3648-53. https:/ / doi.org/10.1128/ IAI.65.9.3648-3653.1997
14. Charuchaimontri C, Suputtamongkol Y, Nilakul C, Chaowagul W, Chetchotisakd P, Lertpatanasuwun N, et al. Antilipopolysaccharide II: an antibody protective against fatal melioidosis. Clin Infect Dis. 1999;29:813-8. https:// doi.org/10.1086/520441

15. Vasu C, Vadivelu J, Puthucheary SD. The humoral immune response in melioidosis patients during therapy. Infection. 2003;31:24-30. https://doi.org/10.1007/s15010-002-3020-2

16. Chenthamarakshan V, Kumutha MV, Vadivelu J, Puthucheary SD. Distribution of immunoglobulin classes and IgG subclasses against a culture filtrate antigen of Burkholderia pseudomallei in melioidosis patients. J Med Microbiol. 2001;50:55-61. https:// doi.org/10.1099/0022-1317-50-1-55

17. Pumpuang A, Phunpang R, Ekchariyawat P, Dulsuk A, Loupha S, Kwawong K, et al. Distinct classes and subclasses of antibodies to hemolysin co-regulated protein 1 and O-polysaccharide and correlation with clinical characteristics of melioidosis patients. Sci Rep. 2019;9:13972. https://doi.org/10.1038/s41598-019-48828-4

18. Chaichana P, Chantratita N, Brod F, Koosakulnirand S, Jenjaroen $\mathrm{K}$, Chumseng $\mathrm{S}$, et al. A nonsense mutation in TLR5 is associated with survival and reduced IL-10 and TNF-a levels in human melioidosis. PLoS Negl Trop Dis. 2017;11:e0005587. https://doi.org/10.1371/journal. pntd.0005587

19. Wuthiekanun V, Langa S, Swaddiwudhipong W, Jedsadapanpong W, Kaengnet Y, Chierakul W, et al. Short report: melioidosis in Myanmar: forgotten but not gone? Am J Trop Med Hyg. 2006;75:945-6. https://doi.org/10.4269/ ajtmh.2006.75.945

20. Alexander AD, Huxsoll DL, Warner AR Jr, Shepler V, Dorsey A. Serological diagnosis of human melioidosis with indirect hemagglutination and complement fixation tests. Appl Microbiol. 1970;20:825-33. https://doi.org/10.1128/ AM.20.5.825-833.1970

21. Bruhns P, Iannascoli B, England P, Mancardi DA, Fernandez N, Jorieux S, et al. Specificity and affinity of human Fcgamma receptors and their polymorphic variants for human IgG subclasses. Blood. 2009;113:3716-25. https:/ / doi.org/10.1182/blood-2008-09-179754

22. Warmerdam PA, van de Winkel JG, Vlug A, Westerdaal NA, Capel PJ. A single amino acid in the second Ig-like domain of the human FC gamma receptor II is critical for human IgG2 binding. J Immunol. 1991;147:1338-43.

23. Arthur MF, Yee HMP, Zuniga R, Salmon JE, Musher DM. Association between FcgRIIa-R131 allotype and bacteremic pneumococcal pneumonia. Clin Infect Dis. 2000;30:25-8. PubMed https:/ / doi.org/10.1086/313588

24. Aucan C, Traoré Y, Tall F, Nacro B, Traoré-Leroux T, F umoux F, et al. High immunoglobulin G2 (IgG2) and low IgG4 levels are associated with human resistance to Plasmodium falciparum malaria. Infect Immun. 2000;68:1252-8. https:// doi.org/10.1128/IAI.68.3.1252-1258.2000

25. Shackelford PG, Granoff DM, Polmar SH, Scott MG, Goskowicz MC, Madassery JV, et al. Subnormal serum concentrations of IgG2 in children with frequent infections associated with varied patterns of immunologic dysfunction. J Pediatr. 1990;116:529-38. https://doi.org/10.1016/ S0022-3476(05)81598-7

26. Siber GR, Schur PH, Aisenberg AC, Weitzman SA, Schiffman G. Correlation between serum IgG-2 concentrations and the antibody response to bacterial polysaccharide antigens. N Engl J Med. 1980;303:178-82. https:/ / doi.org/ 10.1056/NEJM198007243030402

27. Amir J, Scott MG, Nahm MH, Granoff DM. Bactericidal and opsonic activity of IgG1 and IgG2 anticapsular antibodies to 
Haemophilus influenzae type b. J Infect Dis. 1990;162:163-71. https://doi.org/10.1093/infdis/162.1.163

28. Aase A, Michaelsen TE. Opsonophagocytic activity induced by chimeric antibodies of the four human IgG subclasses with or without help from complement. Scand J Immunol. 1994;39:581-7. https:// doi.org/10.1111/j.1365-3083.1994. tb03416.x

29. Bindon CI, Hale G, Brüggemann M, Waldmann H. Human monoclonal IgG isotypes differ in complement activating function at the level of $\mathrm{C} 4$ as well as $\mathrm{C} 1 \mathrm{q}$. J Exp Med. 1988;168:127-42. https://doi.org/10.1084/ jem.168.1.127

30. Sawada S, Kawamura T, Masuho Y. Immunoprotective human monoclonal antibodies against five major serotypes of Pseudomonas aeruginosa. J Gen Microbiol. 1987; 133:3581-90.

31. Nagelkerke SQ, Tacke CE, Breunis WB, Tanck MWT, Geissler J, Png E, et al.; International Kawasaki Disease Genetics Consortium. Extensive ethnic variation and linkage disequilibrium at the FCGR2/3 locus: different genetic associations revealed in Kawasaki disease. Front Immunol. 2019;10:185. https://doi.org/10.3389/fimmu.2019.00185
32. van Schie RC, Wilson ME. Evaluation of human $\mathrm{F}$ cgammaRIIA (CD32) and FcgammaRIIIB (CD16) polymorphisms in Caucasians and African-Americans using salivary DNA. Clin Diagn Lab Immunol. 2000;7:676-81. https://doi.org/10.1128/CDLI.7.4.676-681.2000

33. Parren PW, Warmerdam PA, Boeije LC, Arts J, Westerdaal NA, Vlug A, et al. On the interaction of IgG subclasses with the low affinity Fc gamma RIIa (CD32) on human monocytes, neutrophils, and platelets. Analysis of a functional polymorphism to human IgG2. J Clin Invest. 1992;90:153746. https:/ / doi.org/10.1172/JCI116022

34. van Sorge NM, van der Pol W-L, van de Winkel JG. FcgammaR polymorphisms: Implications for function, disease susceptibility and immunotherapy. Tissue Antigens. 2003;61:189-202. https:/ / doi.org/10.1034/ j.1399-0039.2003.00037.x

Address for correspondence: Susanna J. Dunachie, Center for Tropical Medicine and Global Health, Peter Medawar Building for Pathogen Research, South Parks Road, Oxford OX1 3SY, UK; email: susie.dunachie@ndm.ox.ac.uk

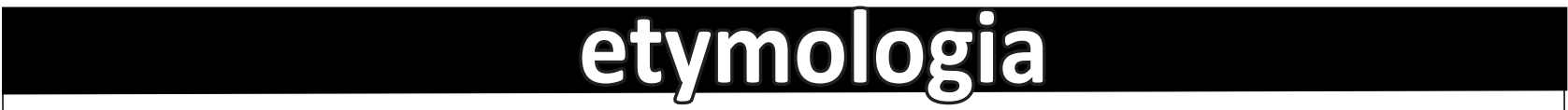 \\ Falciparum [fal-'sI-pə-rəm]}

\section{Aparna Tiwari, Abhinav Sinha}

From the Latin falx or falci (sickle or scythe-

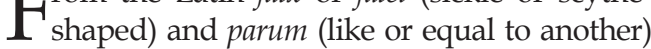
or parere (to bring forth or bear). The species falciparum in the genus Plasmodium is the parasite that causes malignant tertian malaria in humans.

There were many terms suggested for this parasite, such as Ematozoo falciforme by Antolisei and Angelini in 1890 and Haemotozoon falciforme by Thayer and Hewetson in 1895, because of its sickle-shaped gametocytes, the sexual stage of falciparum parasites. However, the term falciparum, suggested by William Henry Welch in 1897, was eventually accepted. In 1954, Plasmodium falciparum (previously Laverania malariae) was approved by International Commission on Zoological Nomenclature.
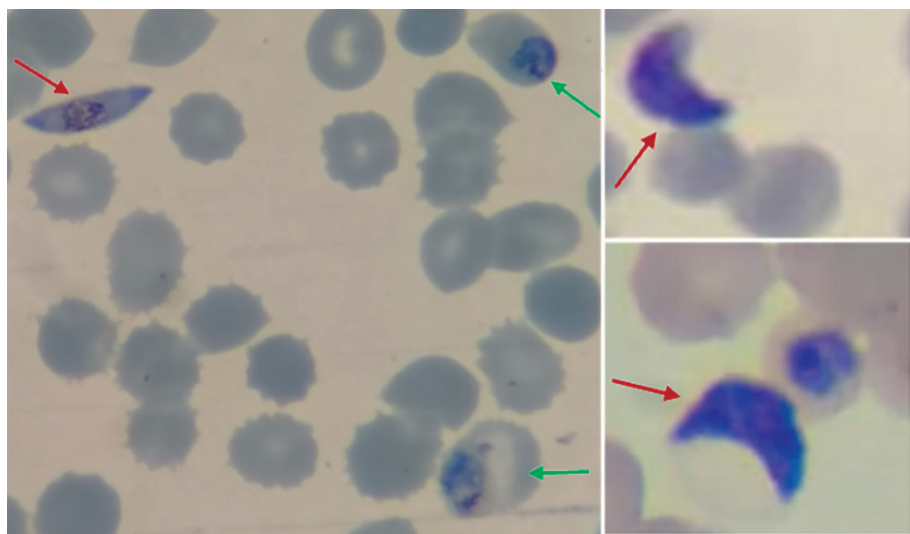

Figure. Giemsa-stained thin blood smear of Plasmodium falciparum (original magnification $\times 1,000$ ). Red arrows indicate gametocytes, and green arrows indicate trophozoite stages. Photograph provided by A. Tiwari.

\section{Sources}

1. Bruce-Chwatt LJ. Falciparum nomenclature. Parasitol Today. 1987;3:252. https://doi.org/10.1016/ 0169-4758(87)90153-0

2. Christophers R, Sinton JA. Correct name of malignant tertian parasite. BMJ. 1938;2:1130-4. https://doi.org/ 10.1136/bmj.2.4065.1130

Author affiliations: Council of Scientific and Industrial Research, New Delhi, India (A. Tiwari); India Council of Medical

DOI: https://doi.org/10.3201/eid2702.ET2702
3. Dorland's illustrated medical dictionary. 32nd ed. Philadelphia: Saunders/Elsevier; 2012. p. 678. 